\title{
V-Kanatçık Kullanımının Havalı Güneş Kollektörlerinde Termal ve Termohidrolik Verime Etkisinin Parametrik Analizi
}

\author{
Cihan YILDIRIM*1 \\ ${ }^{1}$ Adana Alparslan Türkeş Bilim ve Teknoloji Üniversitesi, Mühendislik Fakültesi, Makine \\ Mühendisliği Bölümü, Adana
}

Geliş tarihi: 16.01.2019

Kabul tarihi: 27.03.2019

\section{$\ddot{O} \mathbf{z}$}

Bu çalışmada V-kanatçıklar ile yutucu yüzeyi pürüzlendirilmiş bir hava akışkanlı güneş kollektörünün termal ve termohidrolik verimi sayısal olarak araştırılmış ve farklı pürüzlülük parametrelerinin etkisi incelenmiştir. Pürüzlülük parametrelerinin artması ile termal ve termohidrolik verimin sürekli arttığı bununla beraber rölatif pürüzlülük mesafesi (RRP), rölatif pürüzlülük genişliği (RRW) ve kanatçık açısı $(\alpha)$ parametreleri için belli değerlerden sonra azaldığı gözlemlenmiştir. Bu parametrelere dair optimum değerler $\mathrm{RRP}=8, \mathrm{RRW}=6$ ve $\alpha=60^{\circ}$ olarak belirlenmiștir. Ayrıca V-kanatçıklı yutucu yüzey kullanımının düzlemsel yutucu yüzey kullanımına göre, farklı Reynolds sayılarında, termal verimi \%65 ile \%165 oranında arttırdığı, termohidrolik verimi ise $\% 67$ ile $\% 165$ arasında artırdığı gözlemlenmiş̧tir.

Anahtar Kelimeler: Havalı güneş kollektörü, V-Kanatçık, Termal verim, Termohidrolik verim

\section{Parametrical Analysis of V-Rib Usage in Solar Air Heater on the Thermal and Thermohydraulic Efficiencies}

\begin{abstract}
In this study, thermal and thermohydraulic efficiencies of a solar air heater having roughned absorber plate by V-ribs are numericaly evaluated and the effects of the different roughness parameters on the thermal and thermohydraulic efficiencies are investigated. It is observed that increasing roughness parameters continuesly increases the thermal and thermohudraulic efficiencies; however thermal and thermohydraulic efficiencies decrease after certain point for relative roughnes pitch, relative roughness width and angle of ribs. Optimum points for these parameters are calculated as $R R P=8, R R W=6$ ve $\alpha=60^{\circ}$. In addition to that thermal efficiency is enhanced by $65 \% \sim 165 \%$ and thermohydraulic efficiency is enhanced by $67 \% \sim 165 \%$ for different Reynolds number by using V-rib roughned absorner plate compared to flat plate.
\end{abstract}

Keywords: Solar air heater, V-rib, Thermal efficiency, Thermohydraulic efficiency

"Sorumlu yazar (Corresponding author): Cihan YILDIRIM, dr.cihan.yildirim@gmail.com 


\section{GíRiş}

Güneş enerjisinin düşük sıcaklıklı termal kullanımı üzerine bilimsel çalışmalar gün geçtikçe artmaktadır. Güneş enerjili sıcak su kollektörleri ve bu kollektörler ile çalışan çeşitli ısıtma uygulamaları hakkındaki teknik bilgi kapasitemiz, bilimsel açıdan belli bir doygunluğa ulaşmış ve ticari ürünler olarak günlük kullanıma sunulmuştur. Bununla beraber bu kollektörlerin ve sistemlerin maruz kaldığı önemli sorunlar bulunmaktadır. Kullanılan sudan kaynaklı kireçlenme/korozyon problemleri, suyun donması veya kaynaması kaynaklı riskler ve isıtma amaçlı kullanımlarda karmaşık sistem gereksinimi gibi nedenlerden ötürü araştırmacılar aracı akışkan olarak havanın kullanıldığı sistemler üzerinde çalışmalar yapmaktadır. Güneş enerjili sıcak hava kollektörleri; basit yapıları, üretim için düşük teknoloji gereksinimleri, donma ve kaynama gibi risklerin bulunmaması gibi nedenlerden ötürü binaların ve seraların isitılmasinda ve zirai ürünlerin kurutulmasında sıklıkla kullanılmaktadır. Bunula beraber, güneş enerjili sıcak hava kollektörlerinin termal verimleri, havanın sahip olduğu fiziksel özellikler nedeniyle güneş enerjili sıcak su kollektörlerine göre düşüktür. $\mathrm{Bu}$ mahsurdan ötürü kullanımları güneş enerjili sıcak su kollektörlerine nazaran daha azdır.

Güneş enerjili sıcak hava kollektörlerinin yaygınlaşmasının önündeki bu önemli engel çeşitli araştırmacılar tarafından giderilmeye çalışılmaktadır. $\mathrm{Bu}$ çalışmalar arasında öne çıkanlar ise, toplayıcı yüzeyi üzerinde yapılan değişikliklerle 1Sı transfer katsayısını arttırmaya yönelik çalışmalar, toplayıcı üzerinde $1 \mathrm{~S} 1$ depolamaya yönelik çalışmalar ve 1sı transfer yüzeyini arttırmaya yönelik çalışmalardır [1].

Isı transfer katsayısını ve beraberinde termal verimi artırmaya yönelik olarak araştırmacılar farklı yutucu yüzey tasarımları önermişlerdir [2]. Patil [3] bu yutucu yüzeylerde kullanılan farklı pürüzlülük geometrilerinin kapsamlı bir derlemesini yapmış ve oluşan farklı akış özelliklerinin kollektörlerin termal ve termohidrolik performanslarına etkisini açıklamıştır. Sharma ve Kalamkar [4] farklı pürüzlülük elemanları kullanan kollektörler üzerine detaylı bir inceleme yapmışlar ve bu elemanların farklı kullanımlarından doğan pürüzlülük geometrilerinin, kollektörlerin termohidrolik özelliklerine etkisini göstermişlerdir. Gawande ve arkadaşları [5] ise yaptıkları incelemede, Hesaplamalı Akışkanlar Dinamiği (HAD) yöntemlerinin farklı pürüzlülük geometrilerine sahip kollektörler üzerine uygulamalarını derlemişlerdir. HAD ile yapılan çalışmalar, özellikle deneysel çalışmalarda gözlemlenemeyen pek çok detayı (sınır tabakadaki akışın ayrılma ve birleşme noktaları gibi) vermesi nedeniyle güneş enerjili sicak hava kollektörlerinde sıklıkla kullanılmaktadır.

Güneş enerjili sistemlerin incelenmesinde deneysel çalışmalar ve HAD yöntemleri her ne kadar güvenilir ve detaylı sonuçlar verse de, çok zaman ve masraf gerektiren çalışmalardır. Literatürde bu tür çalışmalar yerine sıklıkla, daha basit olan ve daha hızlı sonuç veren teorik modeller kullanılmaktadır. Kollektörlere ait her detayın bilinmesinin gerekmediği, ama kollektörün verimi ve çıkış sıcaklığı gibi sonuçların hızlı ve doğru bir şekilde hesaplanmasının gerektiği durumlarda torik benzetimler tercih edilmektedirler. Teorik benzetimler aynı zamanda hızlı sonuç üretmeleri nedeniyle parametrik çalışmayı ve dolayısıyla tasarım ve işletme parametrelerinin optimizasyonunu da kolaylaştırmaktadır. Güneş enerjili sıcak hava kollektörlerinin analizinde kullanılan teorik benzetimler üzerine Tchinda [6] kapsamlı bir derleme hazırlamıştır. Yıldırım ve Solmuş [7], kollektör elemanları arasındaki enerji dengesi esasına dayanan bir teorik model ile çift geçişli düzlemsel yutucu yüzeyli bir kolektörün zamana bağlı incelemesini yaparak kanal yüksekliğinin termal ve termohidrolik verime etkisini incelemişlerdir. Hegazy [8] yapmış olduğu teorik analizde güneş enerjili sıcak hava kollektörleri için optimum kanal derinliği/uzunluk oranını tayin etmiştir. $\mathrm{Bu}$ oran arttıkça, hava debisinin artması ile toplayıcı veriminin düştüğünü rapor etmiştir. El-Sebaii ve arkadaşları [9] bir çift geçişli havalı kollektördeki düzlemsel plakalı ve V-oluk plakalı yutucu yüzeyin, termal ve termohidrolik verime etkisini deneysel ve teorik olarak incelemişlerdir. Yıldırım ve Aydoğdu [10] 
oluşturdukları teorik model vasıtasıyla tek geçişli ve çift geçişli havalı kollektörler üzerinde bir optimizasyon çalışması yürütmüştür.

$\mathrm{Bu}$ çalışmada yutucu yüzeyi V-kanatçıklar ile pürüzlendirilmiş bir güneş enerjili sıcak hava kollektörünün termal ve termohidrolik verimi teorik olarak incelenmiştir. Farklı pürüzlülük parametreleri için yapılan benzetimler sonucunda optimum pürüzlülük geometrisinin belirlenmesi amaçlanmıştır. Kollektör yüzeyinde pürüzlülük oluşturmak çoğu zaman imalat maliyetlerine çok az etki etmekte, bununla beraber güneş enerjili sıcak hava kollektörlerinin termal verimlerini önemli oranda iyileştirmektedir. Termal verimdeki bu iyileştirmelerin ise çok fazla hidrolik kayba neden olmaması beklenmektedir. $\mathrm{Bu}$ çalışma ile üretim maliyetlerine etkisinin çok az olduğu düşünülen bir pürüzlülük geometrisi araştırılarak literatüre güneş enerjili sıcak hava kollektörlerinin verimlerinin artırılmasına yönelik katkı sağlanması amaçlanmıştır.

\section{SISTEM TANIMI VE TEORIK BENZETIM}

Teorik benzetimi yapılan kollektörün şematik çizimi Şekil 1'de gösterilmiştir. İncelenen kollektörün bileşenleri yukarıdan aşağıya doğru şu şekildedir: Cam örtü, hava kanalı, yutucu yüzey, izolasyon malzemesi ve kollektör tabanı.



Şekildeki gösterime göre, hava kollektöre sol taraftaki açıklıktan girerek yutucu yüzey ve cam örtü arasında akar. Bu sırada, güneş 1şınlarını yutan yutucu yüzey, kazandığı 1sının önemli bir kısmını havaya taşınım ile aktarılır. Geri kalan miktarı ise tabandan iletim ve cam örtüden ışınım ile kaybedilir. Isınan hava kollektörün diğer tarafında bulunan açıklıktan çıkar. Yutucu yüzey ile hava arasındaki 1sı transferinin iyileştirilmesi için yutucu yüzey üzeri V-kanatçıklar ile pürüzlendirilir. Farklı kanatçık yükseklikleri, farklı kanatçık dizilimleri ve farklı kanatçık sayılarının kullanımı sistem üzerinde farklı pürüzlülük parametrelerinin oluşmasına neden olur.

İncelemeye konu olan pürüzlülük parametreleri sırasıyla şunlardır: Kanatçı yüksekliğinin hidrolik çapa oranı olan rölatif pürüzlülük yüksekliği $(\mathrm{RRH}=\mathrm{e} / \mathrm{D})$, akışa dik yöndeki iki ardışık kanatçık arası mesafenin kanatçık yüksekliğine oranı olan rölatif pürüzlülük mesafesi $(\mathrm{RRP}=\mathrm{P} / \mathrm{e})$, kollektör genişliğinin kanatçık genişliğine oranı olan rölatif pürüzlülük genişliği $(\mathrm{RRW}=\mathrm{W} / \mathrm{W})$, kanatçık ile akış doğrultusu arasında kalan açı olan kanatçık $\operatorname{açisi~}(\alpha)$.

Sistemin teorik benzetimi için kollektör bileşenleri arasındaki enerji dengesinin yazılması gereklidir. Belirli meteorolojik veriler kullanılarak farklı parametre setleri için yapılacak olan hesaplamalarla kollektörün termal ve termohidrolik verimi hesaplanır.

Yapılan teorik benzetimde hesaplamaları kolaylaştırmak için bir takım kabuller yapılmıştır. Bunlar:

- $\quad$ Sistemde hava kaçağı nedeniyle oluşan kütle kayb1 yoktur.

- Toplayıcıdaki hava sıcaklığı akış boyunca doğrusal olarak değişir.

- Toplayıcıda laminer $(\operatorname{Re}<2300)$ ya da türbülanslı (Re>2300) akış tam olarak gelişmiştir(Düzlemsel yüzeyli yutucu için).

- Yutucu yüzeye gelen güneş 1şınımı değeri $500 \mathrm{~W} / \mathrm{m}^{2}$, rüzgar hızı değeri $1 \mathrm{~m} / \mathrm{s}$, dış ortam sıcaklığ $110{ }^{\circ} \mathrm{C}$, kolektör eni $1 \mathrm{~m}$, kolektör boyu $2 \mathrm{~m}$, kanal yüksekliği $5 \mathrm{~cm}$ kabul edilmiştir. Kollektör tabanının $10 \mathrm{~cm}$ 
kalınlığında cam yünü $(\mathrm{k}=0,040 \mathrm{w} / \mathrm{mK})$ ile izole edildiği kabul edilmiştir.

Kollektörü oluşturan her eleman için yazılan zamandan bağımsız enerji Eşitlikleri, MATLAB ortamında program hazırlanarak hesaplanmıştır [7].

Cam örtü:

$I \propto_{g} A_{c}-q_{c, g-a m b}-q_{r, g-s k y}+q_{r, p-g}+q_{c, a-g}=0$

Hava kanalı:

$\mathrm{q}_{c, p-\mathrm{a}}-\mathrm{q}_{\mathrm{c}, \mathrm{a}-\mathrm{g}}-\dot{\mathrm{m}} \mathrm{c}_{\mathrm{p}}\left(\mathrm{T}_{\text {out }}-\mathrm{T}_{\text {in }}\right)=0$

Yutucu yüzey:

$I \propto_{p} \tau_{g} A_{c}-q_{c, p-a}-q_{r, p-g}-q_{l o s s}=0$

Enerji dengesinin yazılması sonucu elde edilen eşitlik seti matris formunda yazılır:

$[\mathrm{A}][\mathrm{T}]=[\mathrm{B}]$

Eşitlik 4'de yer alan $[A]$ matrisi 1 s1 transfer katsayılarının hesaplanması ile oluşturulur. Taşınım ve 1şınım ile olan 1sı transferine ait katsayıların hesabı Yıldırım ve Solmuş [7] tarafindan detaylıca ele alınmıştır. $[B]$ vektörü bilinen değerlerin (Güneş 1şııımı vs.) hesaplanmasından elde edilir. $[T]$ vektörü ise çözüm için gerekli olan kollektör elemanlarının ve çıkan havanın sıcaklık değerlerini ifade etmektedir.

Is1 transfer katsayılarının belirlenmesi için kollektör elemanlarının sıcaklık değerlerinin bilinmesi gerekmektedir. Sicaklık değerlerinin bilinmiyor olması nedeniyle Eşitliğin her iki tarafinda da bilinmeyenler mevcuttur. Dolayısıyla sistem iteratif çözüme ihtiyaç duyar. Başlangıçta tahmini olarak dış ortam sıcaklık değeri kullanılarak yapılan hesaplamalar neticesinde, önce 1S1 transfer katsayıları ardından da Eşitlik 4'ün çözümünden kollektör elemanlarının ve çıkan havanın sıcaklık değerleri hesaplanır. Elde edilen sıcaklık değerleri ile başlangıçta yapılan tahmin karşılaştırılır. Çıkan sonuç, tüm sıcaklık değerleri için $0,01{ }^{\circ} \mathrm{C}$ 'den daha yüksek ise, hesaplanan yeni sıcaklık değerleri bir sonraki iterasyonun tahmini değerleri olarak kullanılır ve hesaplamalar tekrar edilir. Yapilan iterasyonlar sonrasinda sicaklık farkları $0,01{ }^{\circ} \mathrm{C}$ 'den daha düşük ise iterasyon sonlandırılır ve en son hesaplanan sıcaklık değerleri nihai sonuç olarak kabul edilir.

İncelemeye konu olan yutucu yüzey geometrisindeki akışa ve 1 sı transferine ait sürtünme katsayısı ve Nusselt sayıs1 için literatürdeki bir deneysel çalışmadan (Hans ve arkadaşları [11]) elde edilen korelasyonlar kullanılmıştır.

$$
\begin{aligned}
& \mathrm{f}=4,47 \times 10^{-4} \mathrm{Re}^{-0,3188} \mathrm{RRH}^{0,73} \mathrm{RRW}^{0,22} \mathrm{RRP}^{8,9}\left(\frac{\alpha}{90}\right)^{-0,39} \\
& \times \exp \left(-0,52[\ln (\alpha / 90)]^{2}\right) \exp \left(-2,133[\ln (\mathrm{RRP})]^{2}\right)
\end{aligned}
$$

$\mathrm{Nu}=3,35 \times 10^{-5} \mathrm{Re}^{0,92} \mathrm{RRH}^{0,77} \mathrm{RRW}^{0,43} \mathrm{RRP}^{8,54}\left(\frac{\alpha}{90}\right)^{-0,49}$

$\times \exp \left(-0,1177[\ln (\mathrm{RRW})]^{2}\right) \times \exp \left(-0,61[\ln (\alpha / 90)]^{2}\right)$

$\times \operatorname{ex}\left(-2,0407[\ln (R R P)]^{2}\right)$

Pürüzlendirilmiş yüzey ve düzlemsel yüzey arasındaki farkı karşılaştırmak için hesaplamalar düzlemsel yüzeyli yutucu için de yapılmıştır. Bu durumda kullanılan sürtünme katsayısı ve Nusselt sayısı ise laminer akışta:

$f=16 / \operatorname{Re}$

$\mathrm{Nu}=4,9+\frac{0,606\left(\operatorname{RePr}_{\mathrm{L}}\right)^{1,2}}{1+0,0909\left(\operatorname{RePr}_{\mathrm{L}}^{\mathrm{D}}\right)^{0,7}{ }^{0}{ }^{0,17}}$

ve türbülanslı akışta:

$f=(0,79 \ln (R e)-1,64)^{-2}$

$\mathrm{Nu}=\frac{\frac{\mathrm{f}}{8}(\mathrm{Re}-1000) \operatorname{Pr}}{1+12,7\left(\frac{\mathrm{f}}{8}\right)^{0,5}\left(\mathrm{Pr}^{0,67}-1\right)}$

Eşitliklerde kullanılan ifadeler; hidrolik çap $\left(\mathrm{D}=2 \mathrm{WD}_{\mathrm{c}} /\left(\mathrm{W}+\mathrm{D}_{\mathrm{c}}\right)\right)$, kollektör uzunluğu $(L)$, 
Reynold sayısı $(\mathrm{Re}=\mathrm{VD} / \mathrm{v})$ ve Prandtl sayısıdır $(\operatorname{Pr}=\mathrm{v} / \alpha)$.

Eşitlik 4'ün çözümünden elde edilen kollektör çıkış sıcaklığı kullanılarak termal verim değeri hesaplanır:

$\eta_{T}=\frac{\dot{m} c_{p}\left(T_{\text {out }}-T_{\text {in }}\right)}{\text { I.A } A_{c}}$

Termohidrolik verim ise sistemdeki basınç kayıplarını bertaraf etmek için gerekli olan fan gücünün termal verim değerinden çıkarılması ile hesaplanır [7, 9].

$\eta_{\mathrm{TH}}=\frac{\mathrm{mc}_{\mathrm{P}}\left(\mathrm{T}_{\text {out }}-\mathrm{T}_{\text {in }}\right)-\mathrm{P}_{\text {fan }}}{\mathrm{IA}_{\mathrm{c}}}$

Fan gücünün belirlenmesinde El-Sebaii ve arkadaşları [9] takip ettiği metodolojiden faydalanılmıştır. Fan gücünün hesaplanmasına dair ayrıntılar Yıldırım ve Solmuş [7] tarafından ele alınmıştır.

Yapılan teorik benzetimde kullanılan pürüzlülük parametreleri Çizelge 1'de gösterilmiştir.

Çizelge 1. Hesaplamalarda kullanılan parametre

\begin{tabular}{|c|c|c|c|}
\hline $\begin{array}{c}\text { Rölatif } \\
\text { pürüzlülük } \\
\text { yüksekliği } \\
(\mathrm{RRH}=\mathrm{e} / \mathrm{D})\end{array}$ & $\begin{array}{c}\text { Rölatif } \\
\text { pürüzlülük } \\
\text { mesafesi } \\
(\mathrm{RRP}=\mathrm{P} / \mathrm{e})\end{array}$ & $\begin{array}{c}\text { Rölatif } \\
\text { pürüzlülük } \\
\text { genişliği } \\
(\mathrm{RRW}=\mathrm{W} / \mathrm{w})\end{array}$ & $\begin{array}{c}\text { Kanatç1k } \\
\text { aç1s1 } \\
(\alpha)\end{array}$ \\
\hline 0,019 & 6 & 1 & $30^{\circ}$ \\
\hline 0,026 & 8 & 2 & $45^{\circ}$ \\
\hline 0,035 & 10 & 3 & $60^{\circ}$ \\
\hline 0,043 & 12 & 4 & $75^{\circ}$ \\
\hline & & 5 & \\
\hline & & 7 & \\
\hline & & 8 & \\
\hline & & 10 & \\
\hline & & & \\
\hline & & 6 & \\
\hline
\end{tabular}

\section{ANALIZZ VE BULGULAR}

Hazırlanan bilgisayar programı vasitasıyla Çizelge 1'de verilen parametrelerin değişiminin termal ve termohidrolik verime etkisi araştırılmıştır.

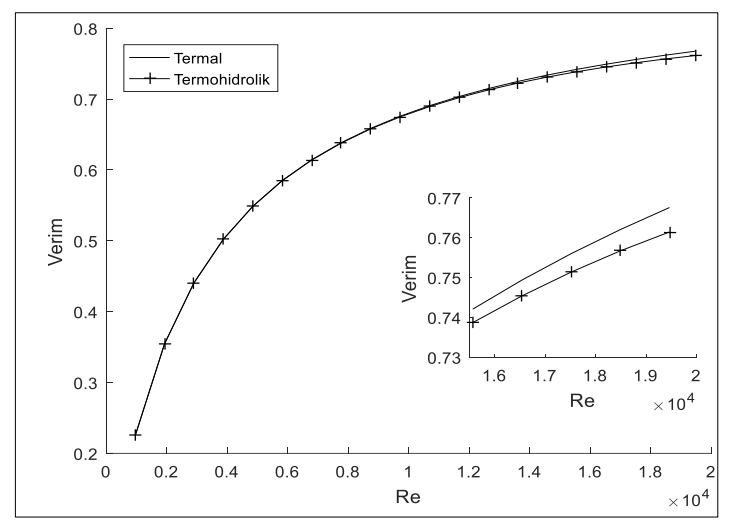

Şekil 2. Termal ve termohidrolik verimin Reynolds sayısı ile değişimi $\left[\mathrm{RRH}=0,043, \mathrm{RRP}=8, \mathrm{RRW}=6, \alpha=60^{\circ}\right.$ ]

Şekil 2'de, belirtilen parametre değerleri için termal ve termohidrolik verimin Reynolds sayısına göre değişimi gösterilmektedir. Termal verim ve termohidrolik verim Reynolds sayısının artmasıyla artış göstermektedir. Düşük Reynolds sayılarında akışın neden olduğu basınç kaybı çok az olduğundan, bu değerlerde termal ve termohidrolik verim değerleri neredeyse birbirine eşittir. Bununla beraber Reynolds sayısının artması neticesinde yutucu yüzeydeki kanatçıkların neden olduğu sürtünme ile oluşan basınç kaybı artmakta ve termal verim ile termohidrolik verim arasındaki fark açılmaktadır (Şekil 2, iç resim).

\subsection{Rölatif Pürüzlülük Yüksekliğinin Termal ve Termohidrolik Verime Etkisi}

Kanatçık yüksekliğinin hidrolik çapa oranını ifade eden rölatif pürüzlülük yüksekliğinin (RRH) artması neticesinde akış içerisinde türbülans oluşmakta ve bu türbülans neticesinde 1s1 transfer katsayısı önemli ölçüde artmaktadır. Isı transfer katsayısının artması hem termal verime (Şekil 3) hem de termohidrolik verime (Şekil 4) olumlu etki etmektedir. 


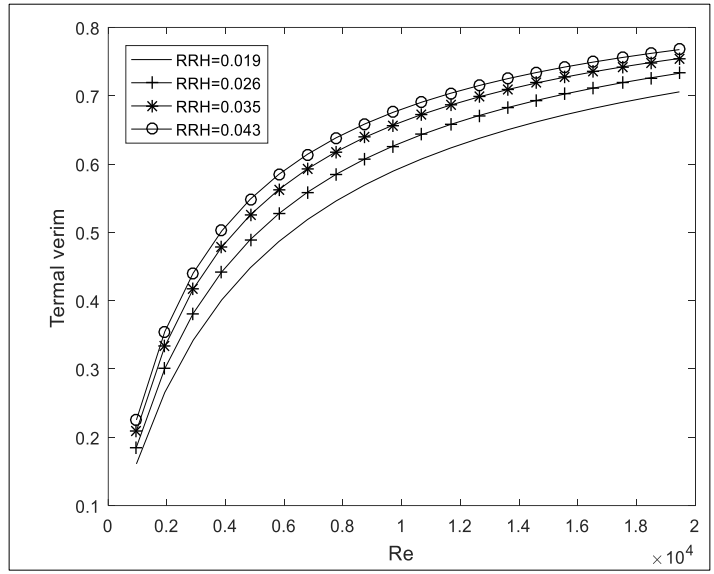

Şekil 3. Termal verimin rölatif pürüzlülük yüksekliği $[\mathrm{RRH}]$ ile değişimi $[\mathrm{RRP}=8$, $\left.\mathrm{RRW}=6, \alpha=60^{\circ}\right]$

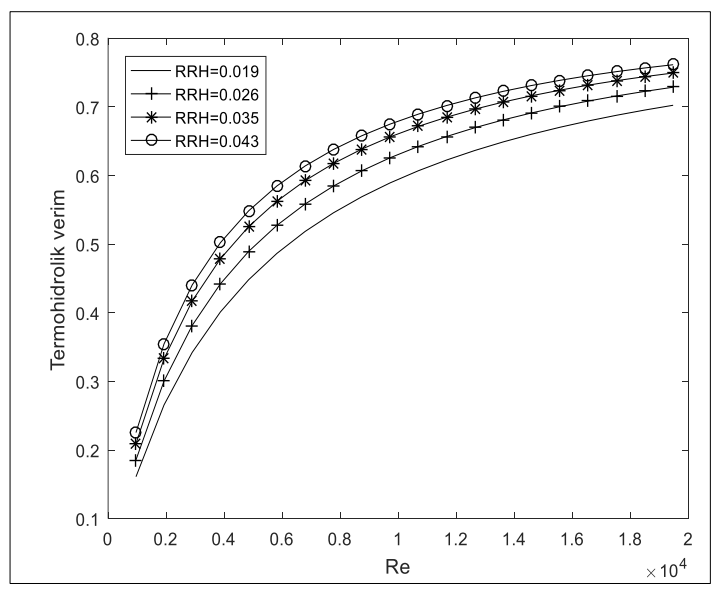

Şekil 4. Termohidrolik verimin rölatif pürüzlülük yüksekliği $[\mathrm{RRH}]$ ile değişimi $[\mathrm{RRP}=8$, $\left.\mathrm{RRW}=6, \alpha=60^{\circ}\right]$

\subsection{Rölatif Pürüzlülük Mesafesinin Termal ve Termohidrolik Verime Etkisi}

Şekil 5'de ve Şekil 6'da rölatif pürüzlülük mesafesinin (RRP) termal ve termohidrolik verime etkisi gösterilmiştir. RRP'nin artması ile her iki verim değeri artmakta fakat $R R P=8$ değerinden sonra azalmaktadır. Bu durumun sınır tabakadan ayrılan akışın, akışa dik yönde iki kanatçık arası mesafenin kısa olduğu $(\mathrm{RRP}<8)$ durumda yeniden birleşememesinden kaynaklandığı, iki kanatçık arası mesafenin uzun olduğu (RRP $>8)$ durumda ise ayrılan akıșın kanatçıktan önce yeniden birleşmesinden kaynaklandığı düşünülmektedir (Hans ve arkadaşları [11]). Isı transfer mekanizması ve akış karakteristiği arasındaki bağlantının daha detaylıca anlaşılabilmesi için akış görselleştirme metotlarından faydalanan çeşitli çalışmaların yapılması uygun olacaktır.



Şekil 5. Termal verimin rölatif pürüzlülük mesafesi [RRP] ile değişimi $[R R H=0,043$, $\left.\mathrm{RRW}=6, \alpha=60^{\circ}\right]$



Şekil 6. Termohidrolik verimin rölatif pürüzlülük mesafesi $[R R P]$ ile değişimi $[R R H=0,043$, $\left.\mathrm{RRW}=6, \alpha=60^{\circ}\right]$

\subsection{Rölatif Pürüzlülük Genişliğinin Termal ve Termohidrolik Verime Etkisi}

Şekil 7'de ve Şekil 8'de rölatif pürüzlülük genişliğinin (RRW) termal ve termohidrolik verime etkisi gösterilmiştir. RRW'nin artması ile 
her iki verim değeri artmakta fakat $R R W=6$ değerinden sonra az miktarda azalmaktadır. $\mathrm{Bu}$ azalma binde bir mertebesinde olduğundan, termal ve termohidrolik verim değerleri $R R W=6$ değerinden sonra değişmiyor kabul edilebilir. RRW'nin artması ile akış yönünde daha fazla engel oluşacağı için bunun 1sı transferini arttırıcı bir etken olduğu düşünülmektedir. Bununla beraber $\mathrm{RRW}=6$ değerinden sonra oluşan türbülans 1S1 transferini daha fazla arttırmamaktadır.

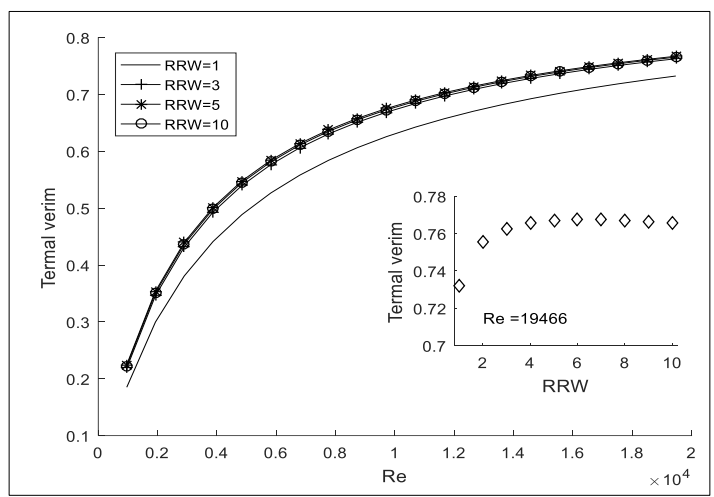

Şekil 7. Termal verimin rölatif pürüzlülük genişliği [RRW] ile değişimi $\left[\mathrm{RRH}=0,043, \mathrm{RRP}=8, \alpha=60^{\circ}\right.$ ]

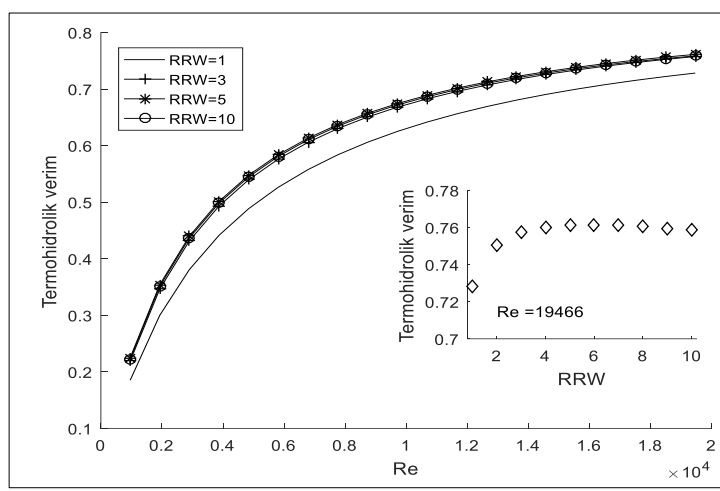

Şekil 8. Termohidrolik verimin rölatif pürüzlülük genişliği [RRW] ile değişimi $\left[\mathrm{RRH}=0,043, \mathrm{RRP}=8, \alpha=60^{\circ}\right]$

\subsection{Kanatçı Açısının Termal ve Termohidrolik Verime Etkisi}

Şekil 9'da ve Şekil 10'da kanatçık açısının $(\alpha)$ termal ve termohidrolik verime etkisi gösterilmiștir. Kanatçık açısının genişlemesi ile kanatçıklar akış önünde daha fazla engel oluşturmuşlar ve yarattıkları türbülans neticesinde 1S1 transfer miktarını arttırmışlardır. Bununla beraber bu artıș belli bir değerden $\left(\alpha=60^{\circ}\right)$ sonra durmuş ve çok az miktarda azalmaya başlamıştır. Azalma binde bir mertebesinde olduğundan ihmal edilebilir seviyededir.

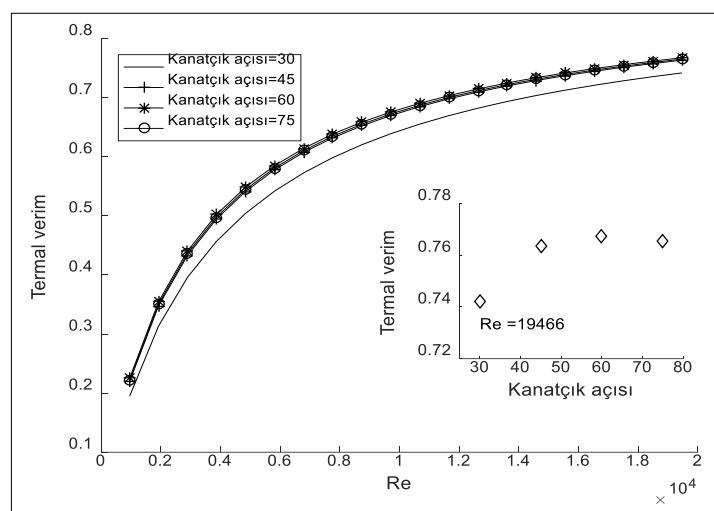

Şekil 9. Termal verimin kanatçık açısı ile değişimi [RRH=0,043, RRP=8, RRW=6]

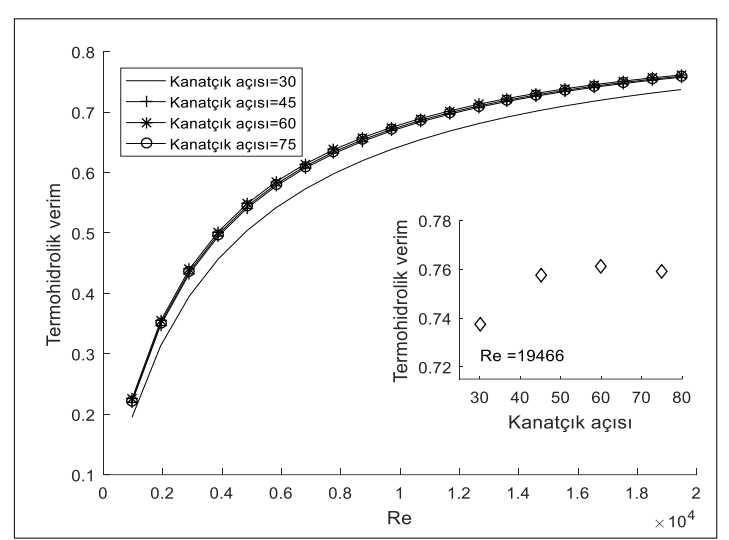

Şekil 10. Termohidrolik verimin kanatçık açısı ile değişimi $\mathrm{RRW}=6$

\subsection{Düzlemsel Yutucu Yüzeyli ve Pürüzlendirilmiş Yutucu Yüzeyli Kollektörlerin Karşılaştırması}

Şekil 11'de ve Şekil 12'de pürüzlendirilmiş yutucu yüzeye sahip kollektör ile düzlemsel yutucu yüzeye sahip kollektörün termal ve termohidrolik 
verim değerleri karşılaştırılmıştır. Pürüzlendirilmiş yutucu yüzey düşük Reynolds sayılarından itibaren her iki verim değerini de arttırıcı bir etki sağlamıştır. Termohidrolik verimin, termal verim gibi yüksek miktarda artış göstermesi kanatçıkların sağladığı termal faydanın (1Sı transferi artı̧̧) hidrolik kayıplarından (basınç düşümü) çok daha fazla olduğunu göstermektedir. Kanatçıklar ile pürüzlendirilmiş yüzeyler termal verim için $\% 65$ ile $\% 165$ oranında, termohidrolik verim için ise \%67 ile \%165 oranında bir artışa imkân vermektedir.

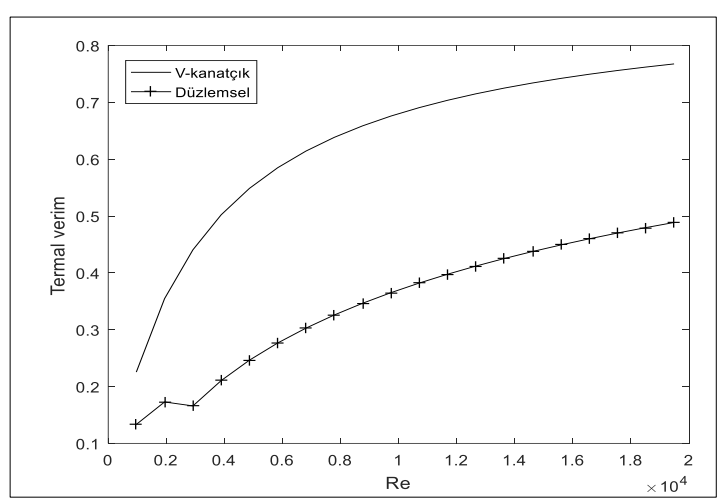

Şekil 11. Düzlemsel yüzeyli yutucu plakaya sahip bir kollektör ile V-kanatlı yutucuya sahip bir kollektörün termal verim değerleri. $\quad[\mathrm{RRH}=0,043, \quad \mathrm{RRP}=8$, $\mathrm{RRW}=6]$



Şekil 12. Düzlemsel yüzeyli yutucu plakaya sahip bir kollektör ile V-kanatlı yutucuya sahip bir kollektörün termohidrolik verim değerleri. [RRH=0,043, $\mathrm{RRP}=8$, $\mathrm{RRW}=6]$

\section{SONUÇ}

$\mathrm{Bu}$ çalışmada, V kanatçıklar ile pürüzlendirilmiş bir yutucu yüzeye sahip hava akışkanlı güneş kollektörünün termal ve termohidrolik verimi, farklı pürüzlülük parametrelerine göre incelenmiş ve düzlemsel yüzeyli kollektörler ile karşılaş̧ırılmıştır. Elde edilen temel bulgular şu şekilde özetlenebilir.

- Reynolds sayısının (yani akışkan debisinin) artmas1 1s1 transfer miktarını arttırıcı bir etki göstermektedir, bununla beraber incelenen Reynolds sayis1 sınırları içerinde çok fazla hidrolik kayba sebep olmamaktadır.

- Rölatif Pürüzlülük Yüksekliğinin artması ile termal ve termohidrolik verim artış göstermektedir.

- Rölatif Pürüzlülük Mesafesinin artmas1 belli bir noktaya kadar $(\mathrm{RRP}=8)$ termal ve termohidrolik verimi arttırmakta, bu noktadan sonra ise azalmasina neden olmaktadir.

- Rölatif Pürüzlülük Genişliğinin artmas1 belli bir noktaya kadar (RRW=6) termal ve termohidrolik verimi arttırmakta, bu noktadan sonra ise ihmal edilebilir seviyede düşüşe neden olmaktadır. Üretim maliyeti açısından düşünüldüğünde kanatçık sayısını 6 ile sinırlandırılması uygun olacaktır.

- Kanatçık açısının artması $60^{\circ}$ dereceye kadar termal ve termohidrolik verimi arttırmakta, bu noktadan sonra ise ihmal edilebilir seviyede düşüşe neden olmaktadır.

- Pürüzlülük geometrileri arasındaki en belirgin katk1 Rölatif Pürüzlülük Yüksekliği (RRH) tarafindan sağlanmıştır. RRH'nin artırılması ile termal ve termohidrolik verim yaklaşık $\% 7$ artırılabilmiştir. Bu oran RRW için yaklaşık \%3,5, RRP için yaklaşık \%3, kanatçık açısı için ise yaklaşık $\% 2$ mertebesindedir.

- Kanatçıklı yutucu yüzey kullanımı düzlemsel yutucu yüzey kullanımına 
göre, farklı Reynolds sayılarında, termal verimi $\% 65$ ile $\% 165$ oranında, termohidrolik verimi ise \%67 ile \%165 oranında arttırmaktadır.

- Yutucu yüzeyin pürüzlendirilmesinin termal ve termohidrolik verimin arttırılmasına katkı sağladığı bilinse de, oluşan akış ve 1sı transfer mekanizmalarının detaylı olarak incelenebilmesi için akış görselleştirme metotları ile yapılacak çalışmalara ihtiyaç vardır. Gelecekte bu yönde yapılacak çalışmalar, elde edilen termal faydayı daha da fazla arttırabilir.

\subsection{Semboller}

$\begin{array}{ll}\mathrm{A}_{\mathrm{c}} & \text { : Kollektör yutucu yüzey alanı } \\ \mathrm{I} & \text { : Kollektöre gelen güneş 1şınımı } \\ & \text { miktarı } \\ \mathrm{Nu} & : \text { Nusselt sayısı } \\ \mathrm{Re} & \text { : Reynold sayısı } \\ \mathrm{RRH} & \text { : Rölatif pürüzlülük genişliği } \\ \mathrm{RRP} & \text { : Rölatif pürüzlülük mesafesi } \\ \mathrm{RRW} & \text { : Rölatif pürüzlülük genişliği } \\ \mathrm{T} & \text { : Sicaklık } \\ \mathrm{f} & : \text { Sürtünme katsayısı } \\ \mathrm{q} & : \text { Isı transferi } \\ \alpha & : \text { Kanatçık açısı } \\ \propto & : \text { Camın yutma-geçirme katsayısı } \\ \eta & : \text { Verim } \\ \dot{m} & : \text { Kütlesel debi }\end{array}$

$\begin{array}{ll}\text { Alt İndisler (Sub-Indexes) } \\ \mathrm{a} & : \text { Hava } \\ \mathrm{amb} & : \text { Diş ortam } \\ \mathrm{c} & : \text { Konveksiyon ile 1si iletimi } \\ \mathrm{g} & : \text { Cam } \\ \mathrm{loss} & : \text { Kollektör tabanında meydana gelen } \\ & \text { kayip } \\ \mathrm{p} & : \text { Yutucu yüzey } \\ \mathrm{r} & : \text { Radyasyon ile 1si transferi } \\ \text { sky } & : \text { Gökyüzü }\end{array}$

\section{KAYNAKLAR}

1. Chamoli, S., Chauhan, R., Thakur, N.S., Saini, J.S., 2012. A Review of the Performance of
Double Pass Solar Air Heater, Renewable and Sustainable Energy Reviews, 16, 481-492.

2. Lanjewar, A.M., Bhagoria J.L., Agrawal M.K., 2015. Review of Development of Artificial Roughness in Solar Air Heater and Performance Evaluation of Different Orientations for Double Arc Rib Roughness, Renewable and Sustainable Energy Reviews, 43, 1214-1223.

3. Patil, A.K., 2015. Heat Transfer Mechanism and Energy Efficiency of Artificially Roughened Solar Air Heaters-A Review, Renewable and Sustainable Energy Reviews, 42, February, 681-689.

4. Sharma, S.K., Kalamkar, V.R., 2015. Thermohydraulic Performance Analysis of Solar Air Heaters Having Artificial Roughness-A Review, Renewable and Sustainable Energy Reviews, 41, 413-435.

5. Gawande, V.B., Dhoble, A.S., Zodpe, D.B., Chamoli, S., 2016. A Review of CFD Methodology Used in Literature for Predicting Thermo-hydraulic Performance of a Roughened Solar Air Heater, Renewable and Sustainable Energy Reviews, 54, 550-605.

6. Tchinda, R., 2009. A Review of the Mathematical Models for Predicting Solar Air Heater Systems, Renewable and Sustainable Energy Reviews, 13, 1734-1759.

7. Yıldırım, C., Solmuş, İ., 2014. Çift Geçişli Hava Akışkanlı Güneş Toplacı Kanal Yüksekliğinin Termohidrolik Verime Etkisinin İncelenmesi, Is1 Bilimi ve Teknigi Dergisi, 34, 111-122.

8. Hegazy, A.A., 2000. Performance of Flat-plate Solar Air Heaters with Optimum Channel Geometry for Constant/variable Flow Operation, Energy Conversion and Management, 44(4), 401-430.

9. El-Sebaii, A.A., Aboul-Enein, S., Ramadan, M.R.I., Shalaby, S.M., Moharram, B.M., 2011. Investigation of Thermal Performance of Double-pass Flat and V-corrugated Plate Solar Air Heaters, Energy, 36, 1076-1086.

10. Yıldırım, C., Aydoğdu, İ., 2017. Artificial Bee Colony Algorithm for Thermohydraulic Optimization of Flat Plate Solar Air Heaters, Journal of Mechanical Science and Technology, 31(7), 3593-3602. 
V-Kanatçık Kullanımının Havalı Güneş Kollektörlerinde Termal ve Termohidrolik Verime Etkisinin Parametrik Analizi

11. Hans, V.S., Saini, R.P., Saini, J.S., 2010. Heat

Transfer and Friction Factor Correlations for a Solar Air Heater Duct Roughened Artificially with Multiple V-ribs, Solar Energy, 84(6), 898-911. 